\title{
«CAPRICHOS» EN EL JARDÍN. FICCIÓN Y REALIDAD EN LA ESCENOGRAFÍA DE LOS ÁMBITOS DE RECREO PÚBLICO DECIMONÓNICOS
}

\author{
POR \\ JOSÉ MANUEL PRIETO GONZÁLEZ \\ Departamento de Historia de \\ la Ciencia, C.E.H. \\ EVA J. RODRÍGUEZ ROMERO \\ Departamento de Historia del \\ Arte, C.E.H.
}

Different components concuring in the gradual gestation of public recreation spaces in Spanish society, especially at Madrid, since the first decades of the $19^{\text {th }}$ Century have been studied in a first article. Now, pavilions, statuary, garden caprices... complete it. We carry on with two kinds of work material: of a part, built works and, of other, academic projects never carried to practice, that served for the attainment of several Architect titles.

Retomamos aquí un discurso interrumpido en otro lugar ${ }^{1}$, renovando nuestro compromiso con los espacios de recreo público decimonónicos. Conviene recordar que habíamos partido de un ideal «jardín de las delicias», cuyo equipamiento quedaría incompleto sin una serie de elementos arquitectónicos que definen en su conjunto la escenografía característica de estos espacios. Nos habíamos ocupado ya de las, por así decirlo, piezas de contorno - accesos, pórticos, galerías-, en las que, casi como un virtual pomerium romano, se cifra la apropiación simbólica de esa porción de suelo urbano destinada al recreo y disfrute de los ciudadanos. Ahora nos adentraremos en su interior con la intención de descubrir los elementos arquitectónicos que definen el argumento de las diversas escenas; nos referimos a los «caprichos» 0 , según la terminología gala, folies (templetes, cenadores, casitas...) y a otros elementos escultóricos, entendidos como creaciones provistas de buenas dosis de ingenio y fantasía, no exentas de un carácter ornamental, pero que encierran alusiones simbólicas en muchos casos. Nuestra propuesta incluye también un proyecto integral en el que se explicitan todos los componentes que concurren en la gestación de estos espacios. Ahora, como entonces, el proceder metodológico es el mismo: primero recalaremos en las pruebas académicas de los alumnos de arquitectura del tercio central de la pasada centuria para, a continuación, establecer las posibles relaciones con ejemplos concretos construidos en las mismas fechas.

Contando 26 años de edad, el madrileño Patricio Rodríguez pedía, en diciembre de 1842, ser admitido a los ejercicios finales para la obtención del título de arquitecto, tras presentar los cinco planos y la correspondiente memoria del que fue su proyecto de pensado, una Casa de Moneda, además del prescriptivo certificado de prácticas, librado por su maestro particular, Custodio T. Moreno. Entre los tres programas que le habían tocado en suerte para la

\footnotetext{
${ }^{1}$ Cfr. A.E.A., n. ${ }^{\circ} 280,1997$.
} 
prueba de repente, elige el que rezaba «un cenador para un jardín, en el que se colocará alguna diversión de aguas, ya sea por medio de estatuas, vasos del antiguo o diferentes surtidores. Planta, elevación y un corte» ${ }^{2}$ (Fig. 1). Realmente, parece mentira que se trate de un ejercicio de repente dado lo acabado del proyecto; y es que era requisito indispensable para ser admitido al ejercicio de preguntas, que el diseño de esta prueba estuviera «metido en tintas y manchados los esbatimentos» (sombras). Es una estructura de planta circular que consta de un núcleo central y un pasillo envolvente, separados por ocho columnas que, en cuatro grupos de dos, enmarcan sendas estatuas sobre pedestales. Más alto que el anillo deambulatorio, el núcleo central se acusa al exterior a través de un tambor octogonal que se cubre a otras tantas vertientes y presenta rosetones en los lienzos de los ejes principales. Los ocho paños de cierre del cuerpo bajo participan igualmente de una moderna formulación neogótica, en la que ojivas con tracería superior y mainel o parteluz constituyen el armazón de unas cristaleras de trazado reticular. El pináculo que corona el conjunto contribuye a potenciar la verticalidad del edificio y, con ello, a acentuar también el historicismo medievalista del diseño. No deja de resultar curioso el maridaje de esta elección estilística y el clasicismo que rezuma el cuerpo basamental en la parte que sirve de frente al estanque, sobre todo por la figura alegórica empotrada en el muro. Asímismo, sorprende esta decidida aproximación al gótico tres años antes de que en Francia tuviera lugar la famosa polémica entre la Academia y la Escuela Gótica. Patricio Rodríguez fue aprobado de maestro arquitecto el $19 \mathrm{de}$ febrero de $1843^{3}$, siendo nombrado poco después Académico de mérito por la Arquitectura ${ }^{4}$; en atención al brillante examen que había realizado para obtener la titulación de Arquitecto, se le dispensó de los ejercicios que disponía el Reglamento para el nombramiento de académico.

Juan Ancell, natural de Bilbao, fue discípulo de Antonio de Zabaleta. Un talento precoz como el suyo se pone claramente de manifiesto al comprobar que, con tan sólo 25 años, los que tenía cuando pidió ser admitido a examen de maestro arquitecto en septiembre de 1846, era profesor de inglés en el Instituto Cántabro de Santander, vocal de la Comisión de Monumentos de la misma provincia y ex-alumno de la Academia de Lymington (Inglaterra). Para la prueba de pensado ideó un edificio con destino a Museo de Artes y Biblioteca. El asunto elegido en la de repente fue «un cenador para un jardín, en el que se colocará alguna diversión de aguas, ya sea por medio de estatuas, vasos del antiguo o diferentes surtidores. Planta, elevación y un corte» ${ }^{5}$ (Fig. 7); es decir, literalmente, se trataba del mismo tema que había desarrollado Patricio Rodríguez tres años antes. Sin embargo, la forma de resolverlo es distinta, aunque mantiene con aquél ciertos puntos de contacto. Así, por ejemplo, Ancell dis-

\footnotetext{
2 Archivo de la Real Academia de Bellas Artes de San Fernando. Legajo 12-2/2. Las otras dos opciones fueron «un puente de madera...» y «un templo de cruz griega...». El enunciado del asunto aparece también en el propio plano, identificado con la sign. A-3526 (Gabinete de Dibujos de la Academia).

Archivo de la Real Academia de Bellas Artes de San Fernando: Registro de los maestros arquitectos aprobados por la Real Academia de Nobles Artes de San Fernando... desde el 28 de agosto de 1816. Sign. 3/154; fol. 29 v., , n. .256.

${ }_{4}$ Patricio Rodríguez ya era Académico de mérito por la Perspectiva en diciembre de 1842. De hecho, sustituía al director de Perspectiva en esta enseñanza; tal puesto había venido siendo desempeñado por su padre, Manuel Rodríguez, hasta que la ceguera le impidió continuar. Archivo de la Real Academia de Bellas Artes de San Fernando. Legajo 12-2/2.

5 Archivo de la Real Academia de Bellas Artes de San Fernando. Legajo 13-6/2. Los programas rechazados por el aspirante fueron: «un altar mayor para una parroquia importante de esta Corte...» y «una fachada de un Palacio Real». El plano del cenador está en el Gabinete de Dibujos de la Academia, sign. A-3528; en él, como señala el autor en una nota, «la planta va indicada a mitad de la escala de los alzados».
} 

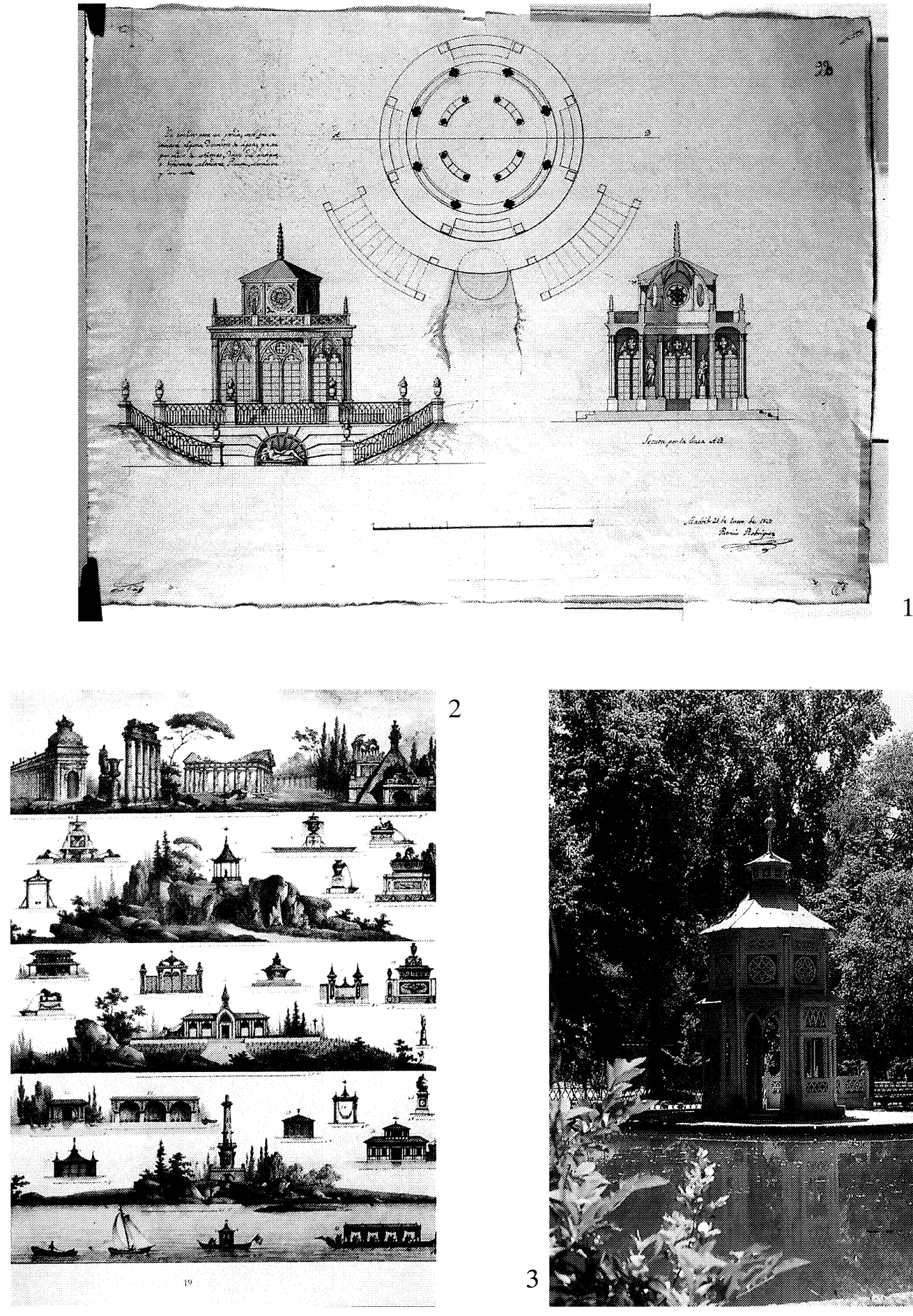

2

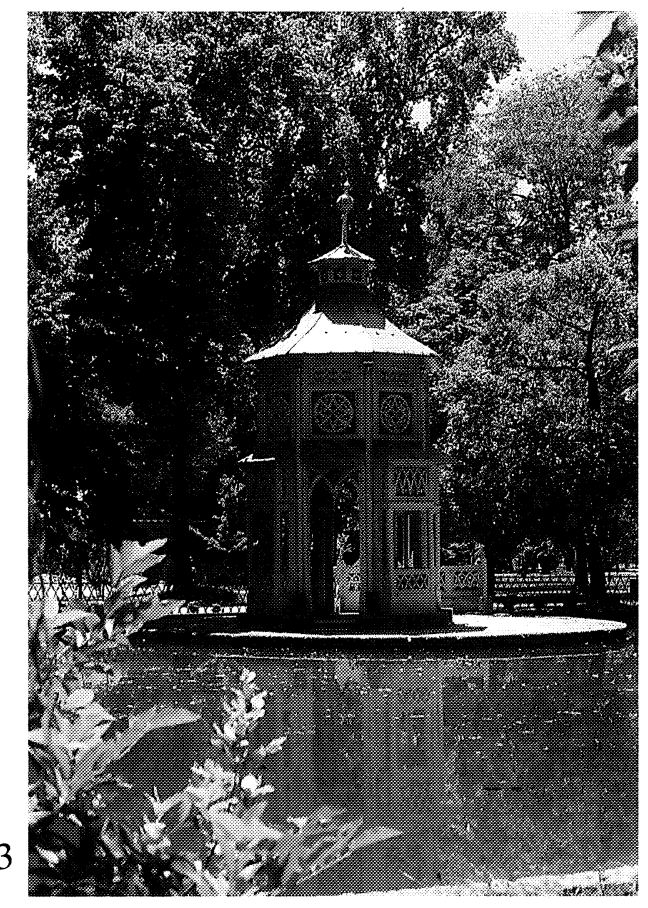

Figuras 1-3. Patricio Rodríguez, Cenador para un jardín, 1843. Lámina con ruinas, fuentes, juegos, puertas, cenadores, embarcaderos... del tratado de Gabriel Thouin, 1820. Estanque de los Chinescos en Aranjuez. Finales del siglo XVIII. Reconstruido en el siglo XIX. 
pone también el cenador sobre un cuerpo basamental —en este caso practicable—, en cuya pared frontal abre una hornacina que recibe una estatua, colocando delante el estanque; asímismo, comunica ambos niveles mediante dos escaleras exteriores y simétricas, que aquí son de doble tramo recto. En cambio, la formulación de este cenador resulta enteramente clásica, recordando, casi de manera arqueológica, la solución del tholos o templo circular griego. En efecto, la estructura del cenador, sumamente sencilla, se limita a una docena de columnas que, dispuestas en círculo, sostienen una cubierta cónica. Teniendo en cuenta la estancia de Ancell en Inglaterra, donde la tradición gótica estaba tan arraigada, tal vez hubiese sido de esperar un diseño más en línea con el de Rodríguez. Juan Ancell fue aprobado de maestro arquitecto el 13 de diciembre de $1846^{6}$.

Del mallorquín Narciso José M. ${ }^{a}$ Bladó, que estudió en la Escuela de Nobles Artes de Barcelona, presentamos, no la prueba de repente, sino uno de los planos («n.. $10 »)$ del proyecto de pensado, que, firmado en la capital catalana el 24 de agosto de 1846, consistió en «un cuartel de militares inválidos» ${ }^{7}$ (Fig. 8). El plano en cuestión incluye los elementos que conformaban el patio principal del cuartel: pórtico de los jardines, surtidor, fuente y obelisco de hierro fundido. Si prescindiéramos del marco arquitectónico para el que fueron concebidos, nada impediría insertar todas estas piezas en nuestro ideal jardín de las delicias. Bladó fue aprobado de maestro arquitecto en Junta General de 1.․․ de noviembre de $1846^{8}$.

Pero nuestro jardín ideal quedaría incompleto sin eso, sin un verdadero jardín al que se subordine la arquitectura y no viceversa. Pues bien, ningún otro proyecto responde mejor a esta premisa que el elaborado por el madrileño Vicente Miranda para la que fue su prueba $d e$ pensado, entregada en marzo de 1853; el programa que le cayó en suerte llevaba el significativo título de «un jardín de recreo público» ${ }^{9}$ (Fig. 13). Buena prueba de la calidad de los diseños realizados es el hecho de que se hizo exposición pública de los mismos. Los siete planos de que consta el proyecto se acompañan de una extraordinaria memoria facultativa ${ }^{10}$, a pesar de que la modestia del aspirante le haga decir que «sólo es un bosquejo de lo que debiera ser». Ante todo, cifra su objetivo en satisfacer las necesidades del programa, sin que ello suponga desatender o renunciar a «nuestras costumbres», reconociendo la completa carencia de jardines públicos en nuestro país ${ }^{11}$, a diferencia de lo que ocurre en el extranjero,

\footnotetext{
6 Archivo de la Real Academia de Bellas Artes de San Fernando: Registro de los maestros arquitectos aprobados por la Real Academia de Nobles Artes de San Fernando... desde el 28 de agosto de 1816. Sign. 3/154; fol. 42 v..$^{\circ}$ n. ${ }^{\circ} 332$.

7 Archivo de la Real Academia de Bellas Artes de San Fernando. Legajo 13-2/2. Entre los tres propuestos, el programa elegido para el ejercicio de repente fue «inventar una iglesia parroquial...» El plano se conserva en el Gabinete de Dibujos de la Academia bajo la sign. A-3527.

8 Archivo de la Real Academia de Bellas Artes de San Fernando: Registro de los maestros arquitectos aprobados por la Real Academia de Nobles Artes de San Fernando... desde el 28 de agosto de 1816. Sign. 3/154; fol. 41 r. $.^{\mathrm{o}}, \mathrm{n} . \mathrm{o} 327$.

$9 \quad$ El título completo rezaba Un jardín de recreo público con espacios para bailes al descubierto, salón cubierto para el mismo, disposición del alumbrado general, orquestas, café, fonda, juegos de todas clases, fuentes, estanques, habitaciones para el servicio, despacho de billetes y demás que contribuya al objeto de diversión. Planta: 0,005 por m.; alzado: 0,015 por m. Gabinete de Dibujos de la Academia de San Fernando, planos A3529 a A-3535.

10 Archivo de la Real Academia de Bellas Artes de San Fernando, legajo 14-5/2: Memoria facultativa del programa $n . \stackrel{0}{4}$. Jardín de recreo público de Vicente Miranda.

$"$ «...al igual que hubiera hecho Larra unos veinte años antes». Ariza Muñoz, M. ${ }^{\text {a }}$ del Carmen: «El jardín en los proyectos de edificios y zonas públicas, hospitales y construcciones religiosas, existentes en la Real Academia de San Fernando de Madrid», en Academia. Boletín de la Real Academia de Bellas Artes de San Fernando; n. $\stackrel{0}{82}$, primer semestre de 1996; pp. 547-569, p. 566. La autora se hace eco de este proyecto de Vicente Miranda.
} 
y planteando en consecuencia la necesidad de establecerlos; dicha necesidad se hacía aun más acuciante en el caso de las grandes poblaciones, en las que, como Madrid, «la gente sobra y el espacio falta». Inicia después un recorrido histórico por el arte de la jardinería, que le lleva a señalar a India y Egipto como los primeros pueblos que se dedicaron a la agricultura, habiendo sido también pioneros en la creación de jardines. No obstante, indica que fueron los chinos los que iniciaron el cultivo de las plantas puramente ornamentales, inventando las estufas calientes para aclimatar en el norte las especies del sur. Dice de los griegos que apreciaban con entusiasmo los jardines y que, de creer a sus poetas, «nada les parecía mejor para recompensar a sus Héroes que colocar sus estatuas en las deliciosas florestas de sus Eliseos». Miranda se refiere en numerosas ocasiones a los jardines como espacios «deliciosos», lo cual supone un espaldarazo a nuestro enfoque de partida. Por lo demás, llama la atención lo bien documentado que estaba este alumno; baste decir que, al hablar de los jardines romanos, se detiene en el de Luculo, cautivado por la celebridad que tuvo el hecho de haberse plantado en él «el primer cerezo que se ha cultivado en Europa», procedente, al parecer, de África.

El discurso del madrileño no abandona en ningún momento la dialéctica de los dos sistemas o estilos de jardín, esto es, el simétrico o regular y el irregular o de paisaje. Reconoce que ningún otro país supera a Inglaterra en jardines de paisaje - del mismo modo que Francia tiene la patente de los simétricos-, pero pone en duda que fueran los ingleses los primeros europeos en cultivarlos, como ellos mismos afirman, ya que, dice, «pretenden haberlos tomado (directamente) de los chinos, por lo que los llaman jardines chinos» ${ }^{12}$. Resulta curiosa su teoría, sobre el seguimiento que se hace en algunos países de uno de estos dos sistemas, basada en una especie de ley del contraste según la cual los paises cultos, que son los agrícolas, se inclinan más por los jardines de paisaje, porque echan de menos los accidentes naturales que hicieron desaparecer al acondicionar sus campos; y viceversa, los «países incultos» o poco cultivados agrariamente, como la India, prefieren jardines regulares y simétricos, porque no hallan esa fisonomía en los terrenos de labor; y es que «el hombre goza en los contrastes y ama la variedad, principio fundamental de todas las artes de imitación» ${ }^{13}$. Del jardín paisajista destaca su encanto y pintoresquismo, señalando que «se abandonan a sus caprichos por conseguir un buen efecto»; y añade: en ellos «se ve con frecuencia violar las reglas de conveniencia local y de unidad, pero siempre para producir emociones fuertes y un placer más fácil de sentir que de razonar» ${ }^{14}$. En su proyecto, tal vez por aquello de que en el justo medio está la virtud, optará por un sistema mixto.

Así pues, un país como España, «al que los antiguos escritores suponían el Jardín de las Espérides», no podía carecer de jardines. Su época de esplendor en esta materia habría sido la undécima centuria, «el siglo más brillante», debido sobre todo a los pintorescos jardines de paisaje creados por los árabes. En cuanto a los tipos de jardines, Miranda deja clara la diferencia entre la antigüedad de los privados y la modernidad de los públicos; asímismo, distingue, entre estos últimos, los que, aun siendo privados en origen, permiten la entrada al público, y los ya creados en principio con ese destino, en los que hay que pagar un módico precio por el

12 Memoria facultativa del programa n. $^{\circ}$ 47. Jardín de recreo público de Vicente Miranda. Op. cit., p. 8. Dice que griegos, italianos y españoles han tenido este tipo de jardines mucho antes que los ingleses, y entonces se ignoraba la existencia de China.

13 Ibidem, p. 10.

14 Memoria facultativa del programa n.ำ 47. Jardín de recreo público... Op. cit., p. 7. «Además -dice-los ingleses no cultivan las flores como objeto de lujo sino de especulación. Sus miras son mayores y las hacen extensivas hasta la ciencia. El primer objeto de un floricultor inglés es enriquecer el dominio de la botánica» (p. 8). 
disfrute de las «diversiones» que proporcionan. Su idea de un auténtico jardín queda lejos de lo que hasta entonces pasaba como tal: «pozos artificiales (...) en los cuales, sobre una o dos docenas de metros cuadrados de terreno, vejetan tristemente algunos árboles raquíticos que, como las flores que a su pie se desarrollan laboriosamente (...), separan cuatro elevados muros»; de hecho, «puede en Madrid llamarse feliz el que tiene un balcón para dedicarse al cultivo de la maceta de albaca, el cajón de claveles o el rosal en tiesto!» ${ }^{15}$. Vicente Miranda piensa en un jardín de grandes plantaciones que coadyuven a purificar la atmósfera, a favorecer las lluvias y a suavizar las temperaturas; un jardín que sea, en suma, un foco de salubridad e higiene. Además, considera obligación de los gobiernos proporcionar a sus gobernados «distracciones baratas e inocentes que les separen de otras que pudieran serles perjudiciales». Con todo, aun no se contempla la gratuidad en este tipo de servicios, quedando sujeto su disfrute a un «corto estipendio»; en este sentido, tal vez cabría hablar de espacios semipúblicos, dado que no todo el mundo podría permitirse ese lujo.

El jardín de Vicente Miranda, pensado en principio para Madrid, es un espacio rectangular cerrado por una cerca de mampostería con verdugadas de ladrillo y machones. La elección de este tipo de cerramiento obedece a consideraciones económicas y estratégicas; en efecto, una verja de hierro sería más cara y, además, permitiría un disfrute visual gratuito desde el exterior; no obstante, dispone esta verja en algunas zonas precisamente para captar clientes, para que a los viandantes de extramuros «les escite la curiosidad y el deseo de entrar a disfrutar de un sitio tan delicioso». Localiza el acceso principal en el flanco meridional, dotándolo de tres buenas puertas de hierro; proximas a ellas, sitúa dos dependencias, una para venta de billetes y la otra para portería. Dentro del jardín dispone una gran plazuela central de la que parten ocho calles radiales. En el mismo núcleo de la plaza ubica un pabellón circular ${ }^{16}$ destinado a baile; cubierto con una bóveda encamonada y calada en su parte central - que pretendía pintar con escenas alegóricas del baile-, este salón cuenta con una galería formada por una columnata de hierro fundido, con antepechos en los intercolumnios, que se repite en el nivel superior; asímismo, incluye zonas para ver y ser visto en relación con el baile. Dos guardarropas, otros tantos tocadores y un par de tiendas de dulces y flores completan el programa del pabellón. Este centro de diversión tiene su contrapunto en una serie de salones de descanso repartidos por otras zonas del jardín, en el que también tienen cabida estatuas, estanques, farolas de gas y candelabros pentaflameros, surtidores, espacios abiertos para la ascensión de globos aerostáticos y fuegos artificiales, una «casita de embarcadero» que termina en un lago con un pabellón de recreo en el centro, zonas para ejercicios gimnásticos, tres estufas para mantener a temperatura idónea una serie de plantas acuáticas y otras flores, y dos plazuelas más, cada una con cuatro fuentes y un edificio para juegos (tiros de pistola y carabina, del gallo, de ballesta, juegos de pelota, billar, naipes, dominó...). Por lo demás, el trazado del jardín sigue, como ya hemos dicho, un sistema mixto; a grandes rasgos, la disposición general de las plazas y de las calles principales rectas (vías rápidas) participa del modelo regular francés; sin embargo, tomados autónomamente, los «parterres» reproducen el tipo paisajista inglés, con callejuelas estrechas y tortuosas que llevan al caminante «de sorpresa en sorpresa», logrando proporcionar así en el menor terreno posible la mayor variedad.

${ }^{15}$ Ibidem, p. 11. «Vivimos — dice- privados de aire, de verdura, de perspectivas naturales (...), respirando polvo y aspirando el ardiente baho de nuestra atmósfera calenturienta».

${ }_{16}$ «Le he dado la forma circular porque he creído la más a propósito para los bailes que hoy estan en uso, como las polkas, valses (...), que todos ellos consisten en esencia en un movimiento de rotación duplo alrededor del centro del salón». Ibidem, p. 15. 
La brillante memoria concluye haciendo mención de ciertos aspectos técnico-constructivos, como la averiguación del espesor de los muros de uno de los pabellones destinados a juegos; del cálculo de costes del salón de baile, estimado en 2.935.811 reales; y de la decoración, entendiendo la belleza en sentido vitruviano como «todo aquello que cumple bien con el objeto a que está destinado, y cuyas partes constitutivas contribuyan al mismo fin». Y es que «no se puede fijar la belleza en base a una regla general» ${ }^{17}$. La filiación estética de los distintos edificios participa de la tolerante doctrina ecléctica.

El proyecto de Vicente Miranda, examinado y aprobado por unanimidad el 14 de marzo de 1853, es mucho más que una prueba de pensado para la obtención del título de arquitecto. Carmen Ariza Muñoz, ha dicho del mismo que «se adelanta incluso a la aparición de los más importantes Jardines de Recreo en nuestra capital, puesto que, (...), el primero de cierta importancia en aparecer sería el denominado Campos Elíseos, surgido en la década de los años sesenta...» ${ }^{18}$. Estamos pues ante una ficción que no hace sino reflejar virtualmente la realidad futura. Son, en efecto, proyectos de papel «atentos a sí mismos», pero, como bien ha dicho Delfín Rodríguez, «es en esa consciente limitación donde encuentran su mayor elocuencia» ${ }^{19}$.

Antes de comentar los principales proyectos de plazas, paseos y zonas públicas de los jadines del tercio central del siglo XIX, nos centraremos en un tema típico en el interior de esos jardines. Se trata de los templetes o «caprichos» de jardín, que procedentes de las arquitecturas de jardín del estilo inglés del XVIII, poblarán con fantasía y delicadeza los rincones y escenas de los jardines paisajistas privados de todo el mundo, para después extenderse también a los nuevos parques públicos en el siglo XIX. En origen, estas fabriques o folies, como se les denominaba en francés, tenían simplemente una función, digamos, ornamental en el jardín, muchas veces simbólica y evocadora. Estas pequeñas construcciones están irremediablemente ligadas al jardín paisajista, que aunque deja, aparentemente, de relacionarse directamente con la arquitectura para inspirarse en la pintura de paisajes, incorpora a la arquitectura en su seno a través de templetes, casitas, ermitas, ruinas, pagodas, etc... que integran el argumento de la escenografía del jardín y van marcando las relaciones espaciales y visuales en el mismo. Circulaban por toda Europa tratados ilustrados con una gran variedad de elementos ornamentales y constructivos para jardines, los cuales serán uno de los vehículos que difundan el jardín paisajista desde Inglaterra y Francia al resto de los países (Fig. 2). Después, en los parques públicos, esas arquitecturas de jardín pasarán a tener también una función utilitaria, albergando en muchos casos diversos servicios para el público que disfruta del jardín. Este tipo de arquitectura ornamental se puso de moda en toda Europa tras la realización del Hameau de M.․․ Antonieta en el Petit Trianon. En España el primer ejemplo que tenemos de estos «caprichos», palabra que se empleó aquí para designar estas pequeñas construcciones ornamentales sin función precisa, son los dos templetes ideados por Juan de Villanueva para el Estanque de los Chinescos en Aranjuez. Uno de ellos, totalmente clasicista, es un bello monóptero construido en piedra y mármol; y el otro, más

17 Ibidem, p. 38.

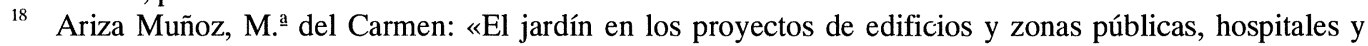
construcciones religiosas, existentes en la Real Academia de San Fernando de Madrid», op. cit., p. 567.

19 Rodríguez Ruiz, Delfín: «Imágenes de lo posible: los proyectos de arquitectura premiados por la Real Academia de Bellas Artes de San Fernando» en VV.AA., Hacia una nueva arquitectura. Premios generales de arquitectura de la Real Academia de Bellas Artes de San Fernando (1753-1831), C.A.M., Madrid, 1992, p. 15. 
original y curioso, con ciertas notas orientales e incluso un cierto y difuso goticismo, es un pabellón de madera policromada (Fig. 3). Precisamente el proyecto que hemos descrito de Cenador para un jardín, realizado en 1843 por Patricio Rodríguez, recuerda algo al pabellón chinesco de Villanueva, aunque, claro está, ya mucho más goticista. El basamente del cenador es, sin embargo totalmente clasicista: con sus balaustradas y escalinatas, el despiece estriado de la piedra, su hornacina de la que parte un curso irregular de agua y que parece albergar lo que podría ser una escultura alegórica de un río, como sucedía en las villas italianas renacentistas. Este basamento guarda una estrecha relación con la imagen de la plataforma sobre la cual Antonio López Aguado levantó el Casino de Baile (Fig. 4) de nuestra villa neoclásica más representativa, la Alameda de Osuna. El Casino se elevaba sobre el final de la ría artificial de dicho jardín y podría haber sido la referencia directa para la inspiración de nuestro alumno. Por otra parte, como hemos comentado, circulaban en la época manuales con láminas de grabados o litografías, que eran compendios de pequeñas construcciones, pabellones, templetes, puentes, etc... que cualquiera podía «copiar» en su jardín. En ellos era frecuente ver la «mezcla» de un cuerpo basamental clasicista sobre el que se elevaba airoso un templete chinesco, por ejemplo (Fig. 5). También abundaban los pabellónes goticistas o exóticos situados sobre elevaciones más naturalistas formadas por promontorios rocosos, algunos naturales y otros artificiales, como por ejemplo el templetillo «chinesco» en los jardines de la Bagatelle o el quiosco o pagoda de Rambouillet. La parte superior, lo que es el templete propiamente dicho, recuerda a las construcciones diseñadas para cubrir las norias del Retiro en el siglo $\mathrm{XIX}^{20}$ (Fig. 6), aunque más diáfano y con una duplicidad espacial interior con la que no contaban estas casetas.

El otro proyecto que comentábamos, realizado por Juan Ancell en 1846, es mucho menos ecléctico y combina la clásica fuente basamental renacentista con un templete rotondo, que, como nota curiosa, se cubre con un cono metálico con lambrequín, al modo de los quioscos de música que proliferan en el XIX en los parques públicos de todas las ciudades españolas. Los caprichos de jardín abundaron en todos los Sitios Reales, como en el Reservado del Retiro remodelado por Fernando VII con proyectos de Isidro González Velázquez, en el Casino de la Reina, en Vista Alegre, en la Casa de Campo, etc..., pues eran un elemento que no podía faltar en los trazados paisajistas. Después se construirán también en los parques y en los squares, surgiendo, como hemos comentado en el artículo anterior, toda una serie de mobiliario urbano inspirado en estas arquitecturas ornamentales.

De los «caprichos» de jardín, pasaremos a otro tema también de gran actualidad en aquel momento. Se trata de los monumentos urbanos en los que el siglo XIX fue tan prolífico. Sin embargo, en esta centuria, para justificar la realización de una obra de ornato público es necesario que vaya acompañada de una razón de utilidad ${ }^{21}$. Pero conmemorar un hecho histórico, por ejemplo, puede ser útil y construir una obra utilitaria, como una fuente, puede ser aprovechado para conmemorar o simbolizar algún acontecimiento. Para ello, se suelen usar modelos consagrados y, en concreto, abundarán algunas formas como los obeliscos cuyo uso principal ha sido, a parte de erigirlos como monumentos conmemorativos, incorporarlos al mun-

20 A.G.P., plano 547.

21 Silva Maroto, M..$^{\text {P }}$ Pilar: «Del Madrid de Carlos III al de Isabel II: ideas, formas e imágenes en la arquitectura de ornato público», en Las propuestas para un Madrid soñado: de Teixeira a Castro, catálogo de la exposición en el Centro Cultural Conde Duque, Madrid, 1992, pp. 87-106, p. 87. Este artículo versa sobre los monumentos de ornato público que se proyectaron y no se realizaron en Madrid en el período que aparece expresado en el título, con independencia de su carácter efímero o permanente, basándose sobre todo en documentación conservada en el Archivo de la Secretaría de la Villa. 

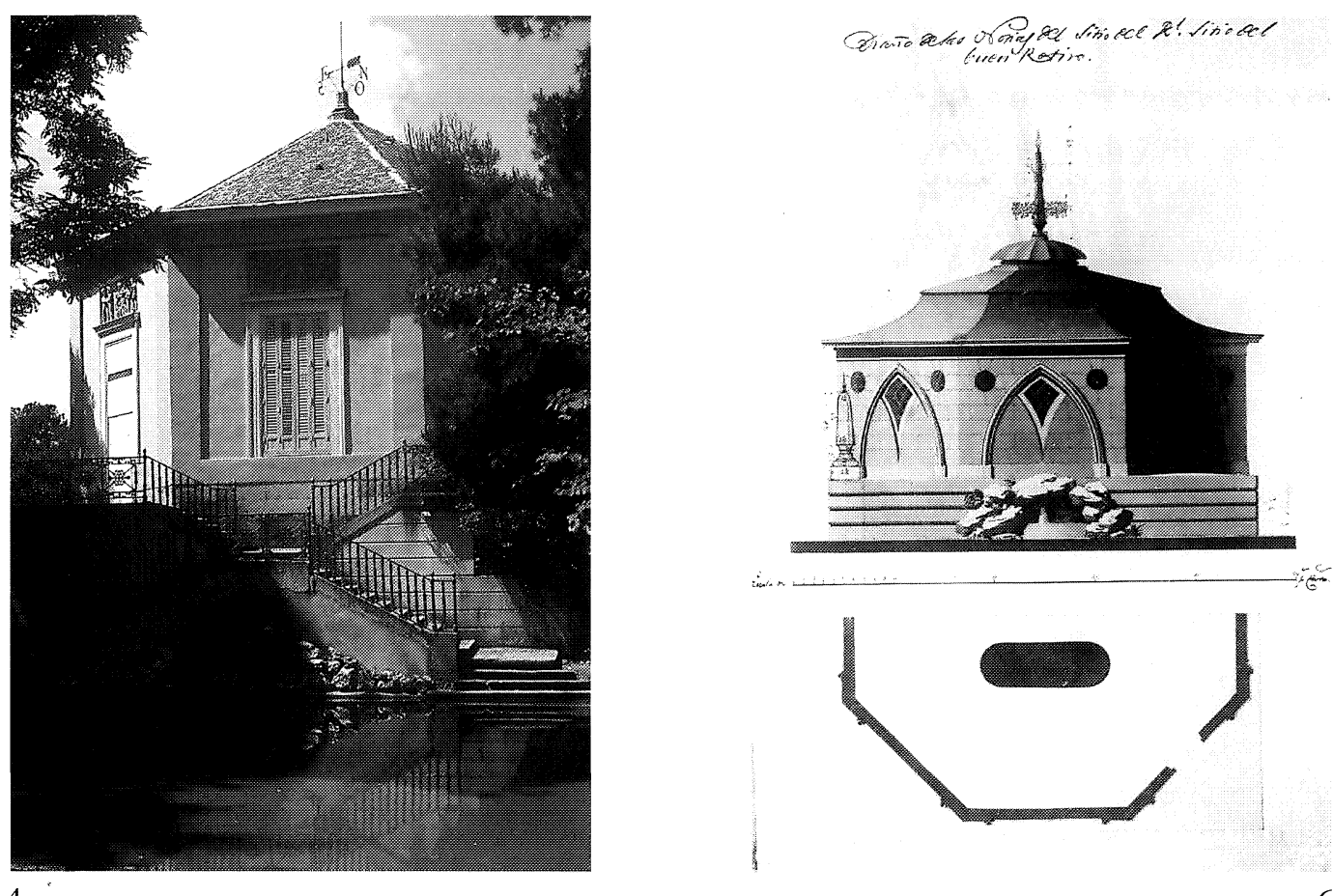

4

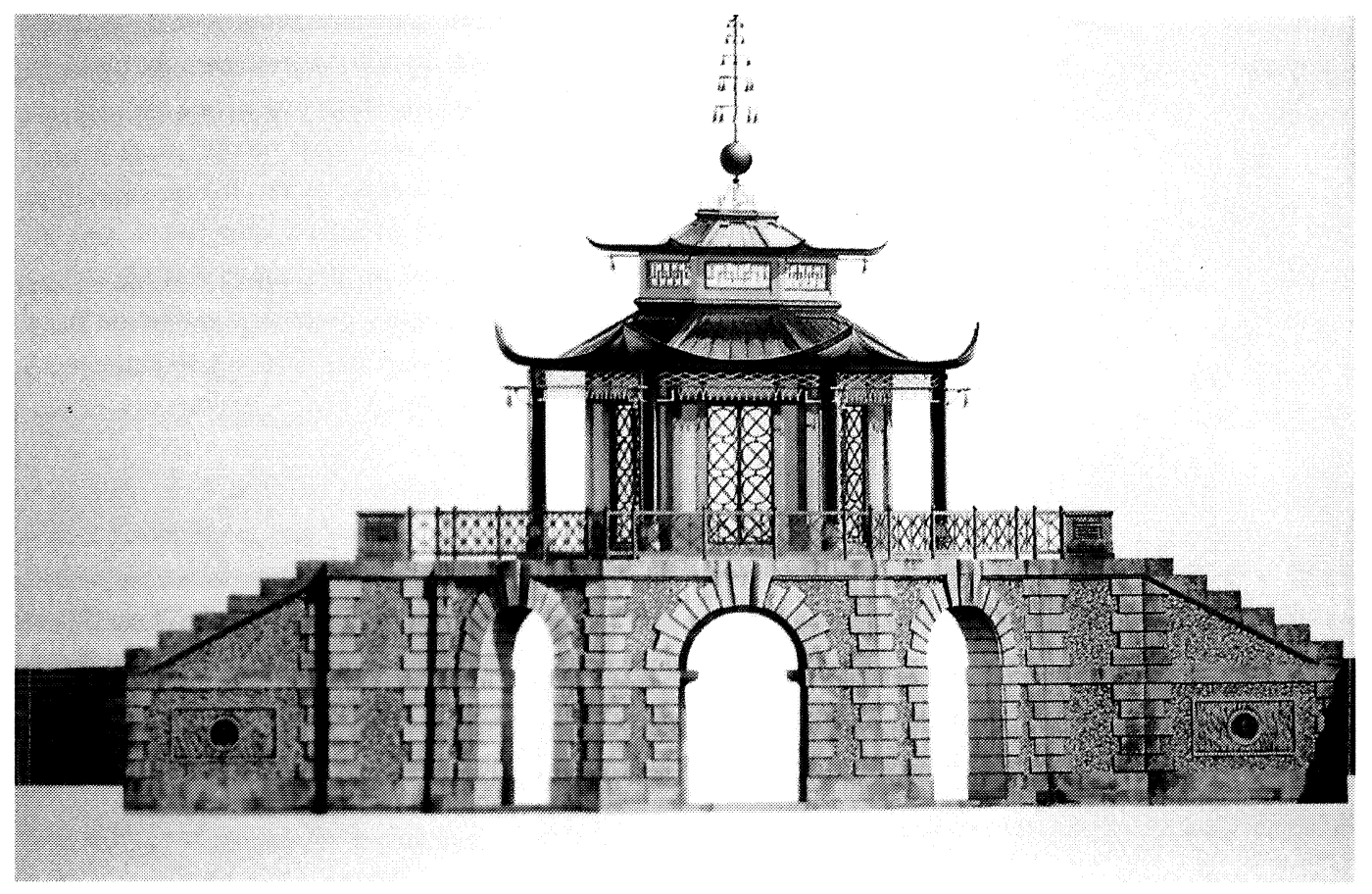

Figuras 4-6. Casino de baile en la Alameda de Osuna. 1815. Pabellón chino en Cassan, Francia, construido hacia 1787. Caseta de noria para el Buen Retiro diseñada en el siglo XIX. 
do del jardín (Fig. 9) para recrear una atmósfera especial, orientalista, misteriosa y exótica ${ }^{22}$. Veremos diversos ejemplos en los que se recurrió a dichas formas «piramidales», los cuales bien podían haber sido fuente de inspiración para el alumno José M. ํ. Bladó.

De los proyectos que se conservan en el Archivo de la Villa de Madrid para las fuentes del Prado, uno representa un obelisco situado sobre dos leones. Debería interpretarse, según Pilar Silva ${ }^{23}$, como un homenaje a la gloria del príncipe, en este caso Carlos III, ya que los leones simbolizan España. Esta alegoría se relacionaría con «la gloria de los príncipes según la medalla de Adriano» que aparecía en la Iconología de Ripa de 1613, que es la que seguramente manejaba Ventura Rodríguez ${ }^{24}$. Dicha imagen presenta un obelisco o «pirámide» apoyado en cuatro esferas, que simboliza «la clara y alta gloria de los príncipes, gracias a cuya magnificencia se edifican los más suntuosos y grandes monumentos que nos muestran su gloria» ${ }^{25}$.

Las pirámides, palabra que sirve para designar igualmente los obeliscos, fueron también frecuentes en los monumentos funerarios, como símbolo de transición entre el cielo y la tierra. Así, por ejemplo, se ha visto un sentido funerario en los dos dibujos arquitectónicos de Goya ${ }^{26}$ (conservados en el Museo del Prado) que representan sendas pirámides, una de ellas oradada por un paso abierto en arco de medio punto, que parece emular una simbólica puerta de ciudad, y la otra, escalonada, apoyada sobre un cuerpo basamental. Estas pirámides tienen mucho que ver con los proyectos monumentales del arquitecto revolucionario Boullée, sobre todo con la Pirámide truncada con frontispicio en nicho y con la llamada Tumba de Hércules. La similitud de formas e ideas entre la obra de Goya y la de Boullée es notoria, ambos traducen sus experimentos plásticos desde su expresividad individualizada con formalismos similares entre los dibujos de arquitectura del pintor y las láminas de proyectos del arquitecto. En cualquier caso, las arquitecturas se presentan como símbolos eternos y como expresión de un colosalismo, se identifican con la sensación expresada, la arquitectura es el monumento. Los monumentos y cenotafios del arquitecto tienen connotaciones similares a los de Goya y cierran esta convergencia expresiva de tal manera que las arquitecturas dibujadas en ambos casos se perfilan en una misma simbología. Además, la gran escala de un monumento y la contundencia expresiva intrínseca a la forma confluyen en la figura clave de la pirámide.

Se podrían buscar también relaciones con posibles contactos con las logias masónicas parisinas que también daban un sentido especial a la forma de la pirámide, que frecuenta tam-

${ }^{22}$ Cfr. Humbert, Jean: «Les obelisques de Paris. Projets et réalisations», Revue de l'art, n. 23 , 1974, pp. 9 y ss.

23 Silva Maroto, M..$^{\text {a }}$ Pilar: «Del Madrid de Carlos III al de Isabel II: ideas, formas e imágenes en la arquitectura de ornato público», op. cit., p. 92.

${ }^{24}$ El programa iconográfico planteado por Ventura Rodríguez ha sido intensivamente estudiado por Thomas Reese: «Hipódromos, carros, fuentes, paseantes y la diversión pública en España del siglo XVIII: un programa agrario y de la antigüedad clásica para el Salón del Prado», en IV Jornadas de Arte. El arte en tiempos de Carlos III, CSIC, Madrid, 1989, pp. 1-47.

25 RIPA: Iconología. Ed. Akal, 1987, I, p. 461.

${ }^{26}$ Sobre estos dibujos, ver: Moreno Villa, José: «Proyecto arquitectónico de Goya», Arquitectura, n.. 110 , 1928, pp. 199-201; Chueca Goitia, Fernando: «Goya y la arquitectura», Revista de Ideas Estéticas, n. ${ }^{\text {s }}$ 15-16, 1946, pp. 431-448; Catálogo de la exposición Goya y la Ilustración, 1988, cat. 116, La gran pirámide, con textos de Jesusa Vega y Ricardo, Usón: «Goya, Pintor-Filósofo: Estética y Arquitectura», en Goya, la Ilustración y la Arquitectura. El Nacimiento del Arte Moderno. Catálogo de la exposición, Colegio Oficial de Arquitectos de Aragón, Zaragoza, 1996, pp. 57-76. 

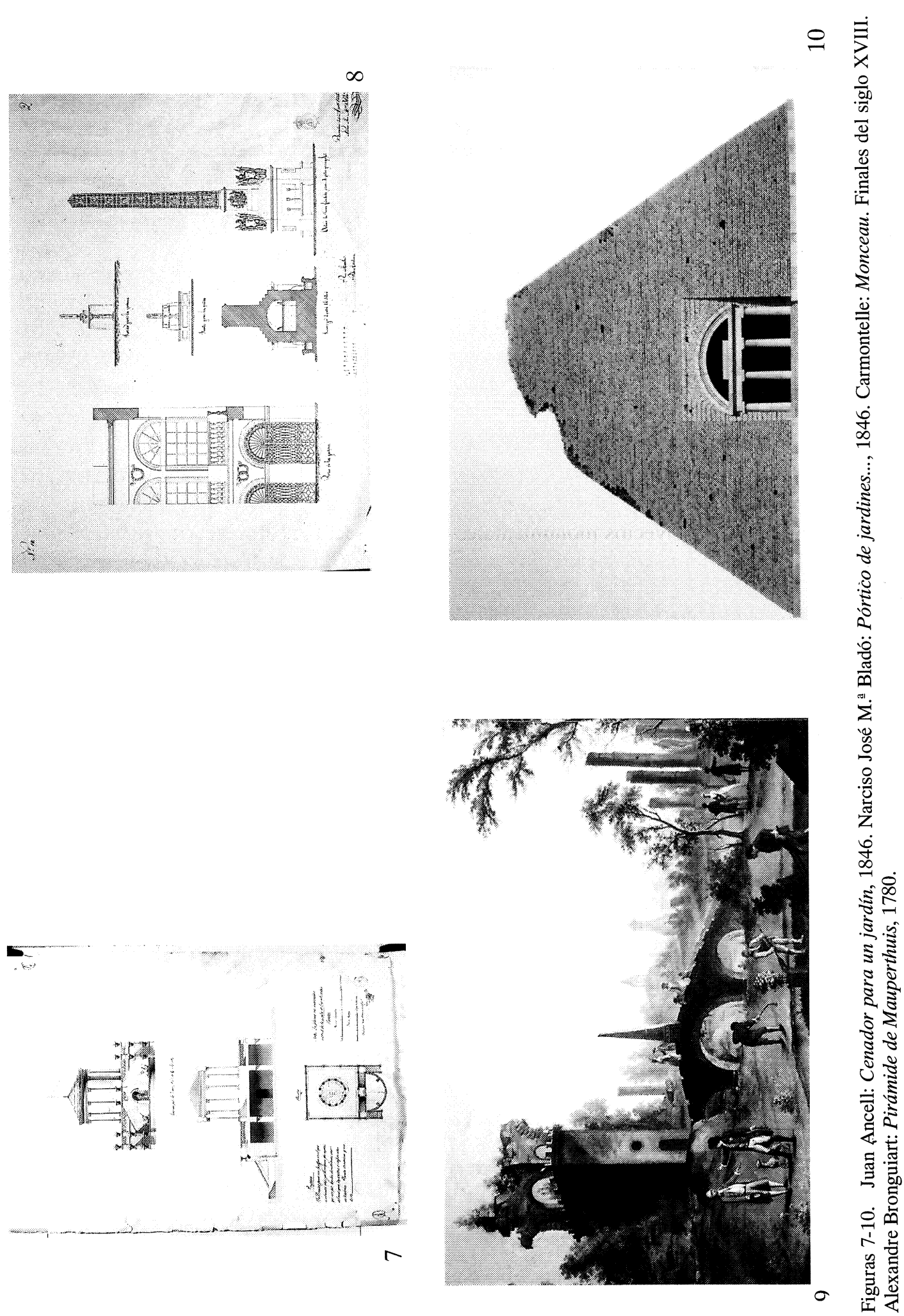
bién el mundo de alusiones escenográficas del jardín. Las fabriques de los jardines paisajistas del siglo XVIII, muchas veces, marcaban las estaciones de un recorrido iniciático-simbólico que podía arrancar de una pirámide, como la de Mauperthuis (Fig. 10), del marqués de Montesquiou, por ejemplo. Esta Entrada al Elíseo era el acceso a un jardín lleno de principios masónicos ${ }^{27}$ y el vínculo de unión entre el jardín regular antiguo y el nuevo trazado paisajista. Curiosamente, la similitud de esta pirámide con la Pirámide truncada con frontispicio... de Boullée es sorprendente.

Pero volvamos al siglo XIX. También un obelisco es el motivo principal del cenotafio para la reina Isabel de Braganza, que Isidro González Velázquez levantara en 1819 en San Francisco el Grande ${ }^{28}$. Así pues, los obeliscos pueden asumir un significado funerario o celebrativo y triunfal.

Según Pedro Navascués, los obeliscos son la forma conmemorativa preferida de los arquitectos fernandinos ${ }^{29}$ como signo inequívoco de cierto romanticismo. Tenemos el ejemplo más tardío, parte del ejercicio de pensado, de Narciso José Bladó en 1846, que proyectó un Pórtico de jardines, con fuente y obelisco. Efectivamente, el obelisco será un tema que se repita en numerosos puntos de la capital desde que fuese elegido para plasmar el monumento a los Caídos el Dos de Mayo de 1808, mediante concurso en $1821^{30}$, y también como motivo de la Fuente del mismo nombre que en 1833 erigió Mariátegui en honor de la Princesa Isabel, al comienzo del paseo a ella dedicado. Este paseo tuvo una especial significación, pues se dedicó una calle —que además marcará el desarrollo de una parte emblemática de la ciudad—al nacimiento de la heredera al trono (tan deseada por los conflictivos años que se vivían) a modo de regalo al pueblo, como nuevo lugar público de esparcimiento. En el proyecto del alumno, el obelisco también se trata de una fuente, aunque parece de dimensiones más reducidas, con un carácter más puntual y aislado, quizás más semejante, aunque en distinta escala, al Monumento del Dos de Mayo rematado en 1840 según el diseño, con ligeras alteraciones, que Isidro González Velázquez había presentado al concurso formulado por el Ayuntamiento.

Obeliscos son también la decoración elegida para la «Glorieta de las Pirámides», que junto con dos fuentes y otras estatuas remataban el conjunto formado por el frondoso Paseo de los «Ocho hilos» (por las ocho hileras de árboles que tenía), que partía de la Puerta de Toledo hasta el Puente de Toledo; así pues, la Glorieta era un ámbito estancial que, a su vez, articulaba la circulación entre el paseo con el acceso al puente, formando un conjunto urbano de gran monumentalidad y belleza, suavizado por la espesura de la vegetación. Como dice Pedro Navascués ${ }^{31}$, «la vista de la Puerta de Toledo desde la otra orilla del Manzanares, viéndose en alto, flanqueada en primer término por los dos obeliscos... debía de ser realmente magnífica».

Existe un precioso plano de la Glorieta de las Pirámides ${ }^{32}$, firmado por Francisco Javier Mariátegui (que parecía adorar los obeliscos) el 22 de septiembre de 1831, que reproducimos

27 Ver Dams, Bernd H.: La folie de bâtir. Pavillons d'agréments et folies sous l'Ancien Régime, Flammarion, París, 1995, pp. 164-165.

28 Pardo Canalís, Enrique: «Cinco cenotafios españoles de 1819 a 1843», Arte Español, t. XVII, 1949, pp. 161-164.

29 Pedro Navascués: Arquitectura y arquitectos madrileños del siglo XIX, Insto. de Estudios Madrileños, Madrid, 1973, p. 35. Las pirámides al modo clásico o al modo egipcio o con forma de obelisco es uno de los temas más repetidos en la arquitectura conmemorativa fernandina.

30 El concurso, convocado por el Ayuntamiento de Madrid, fue publicado en la Gaceta del 31 de mayo de 1821. El monumento se comenzó a construir en 1822, pero no se terminaría hasta 1840. Las vicisitudes del concurso y los proyectos que a él se presentaron son estudiados por Pedro Navascués: op. cit., pp. 34-42.

31 Ibidem, p. 49.

32 A.G.P., sig. 235: alzado y sección de la Glorieta de las Pirámides. El 236 corresponde a la planta. 
(Figs. 11 y 12) para ver cuál era el aspecto de un paseo y una plaza pública creada en estos años del siglo XIX. Siete paseos, tres de ellos principales, confluyen en la plaza; dos obeliscos enmarcan el central y mayor de ellos, el Paseo de los Ocho Hilos, a lo largo del cual se disponen estatuas sobre pedestales dentro de semicírculos verdes trazados con árboles, espaciados equidistantemente, quizás hasta la misma puerta de Toledo. Dos fuentes se ubican a ambos lados de la plaza de planta semicircular abierta hacia el puente de Toledo, mirando al río y al campo. Los bordes de la plaza se «tallan» con hornacinas de árboles que albergan sus respectivas esculturas.

La Glorieta de las Pirámides debió tener en origen, efectivamente, esta imagen, pues tal cual es como la describe Madoz:

Adorna el ingreso a Madrid por esta parte una plaza semicircular de la que parten los tres ramales que se enlazan en la ostentosa puerta de Toledo. Consiste el ornato de la indicada plaza, en dos bellos obeliscos de granito... (que) constan de un zócalo, en el que sientan cuatro cuerpos salientes, dos de ellos almohadillados y terminados por una sencilla cornisa de piedra caliza: sobre dichos cuerpos se levanta en el centro un pedestal que recibe una aguja con 4 bolas de metal. A competentes distancias y formando el semicírculo hay 6 estatuas de la numerosa colección que había en Palacio, si bien estas son mejores que las de la plazuela de Oriente, pues además de estar mas concluidas que aquellas, son de una pieza, contribuyendo á su mejor efecto el hallarse colocadas en pedestales de bastante elevación... Por último 2 cuerpos menores que los referidos obeliscos, pero guardando relación con aquellos en la forma, terminan esta plaza semicircular en los estremos, faltando solamente á cada uno de estos cuerpos un león que le ha de coronar, puesto sobre el tercio de columna con basa dórica que está ya colocado. Entra en el plan hacer 2 fuentes en la embocadura del puente... proyectado todo como la plaza que hemos descrito á fines del reinado de Fernando VII, en cuyo tiempo iba entrando mucho gusto en obras públicas ${ }^{33}$.

No se conoce el motivo por el cual se dispuso el arreglo de esta plaza con la presencia de los dos obeliscos como elementos destacados. El hecho de que los planos se conserven en el Archivo de Palacio nos induce a pensar que se trató de un encargo regio, tal vez decisión de la reina María Cristina que en otras ocasiones mostrará su predilección por el arquitecto Mariátegui a la hora de realizar ciertas adjudicaciones de proyectos. Quizás estos obeliscos, que aparecen sobre pedestales y apoyados en cuatro esferas doradas y acompañados por los leones que cita Madoz, simbología que hemos explicado más arriba, puedan ser un homenaje a la Princesa de Asturias, nacida el año anterior al arreglo de la glorieta.

Pero no será ésta la única plaza que se componga por estas fechas. Veremos, pues, otros ejemplos relacionados con paseos, jardines y plazas. En el anterior artículo comentábamos un proyecto de Narciso Pascual y Colomer cuando aún era estudiante, una Galería para el Paseo de Recoletos. Colomer se graduó como Maestro Arquitecto en 1833 con el proyecto de una Casa de Campo para un soberano y, como si esto fuese una premonición de su carrera, será un arquitecto que tendrá gran vinculación con la jardinería de la época isabelina. No sólo será el promotor de la Escuela de Jardineros Horticultores, sino que realizará numerosas intervenciones como Arquitecto de Palacio y Sitios Reales en proyectos de jardines y también en proyectos para particulares, como la Posesión de Vista Alegre cuando ya pertenecía al marqués de Salamanca ${ }^{34}$. Será el arquitecto que dirigirá las obras del Campo del

33 Madoz, Pascual: Diccionario geográfico-estadístico-histórico de España..., t. X, Madrid, 1847, p. 929.

34 Esta finca, con maravillosos jardines de estilo paisajista (Cfr. Rodríguez Romero, Eva: «Vista Alegre: un jardín romántico», en Medievalismo y Neomedievalismo en la Arquitectura española: el siglo XIX (en prensa)), había sido Posesión Real hasta que en 1859 la compra el marqués de Salamanca y contrata a Colomer para reformarla; el mismo arquitecto había construido hacía poco su palacete con jardines en la Castellana (Cfr. Soto Caba, Victoria: «Narciso Pascual y Colomer, el marqués de Salamanca y los jardines madrileños del período isabelino» en VV. AA.: El palacio del marqués de Salamanca, Argentaria, 1994, sobre todo el punto «el jardín de un banquero», pp. 63-65). 

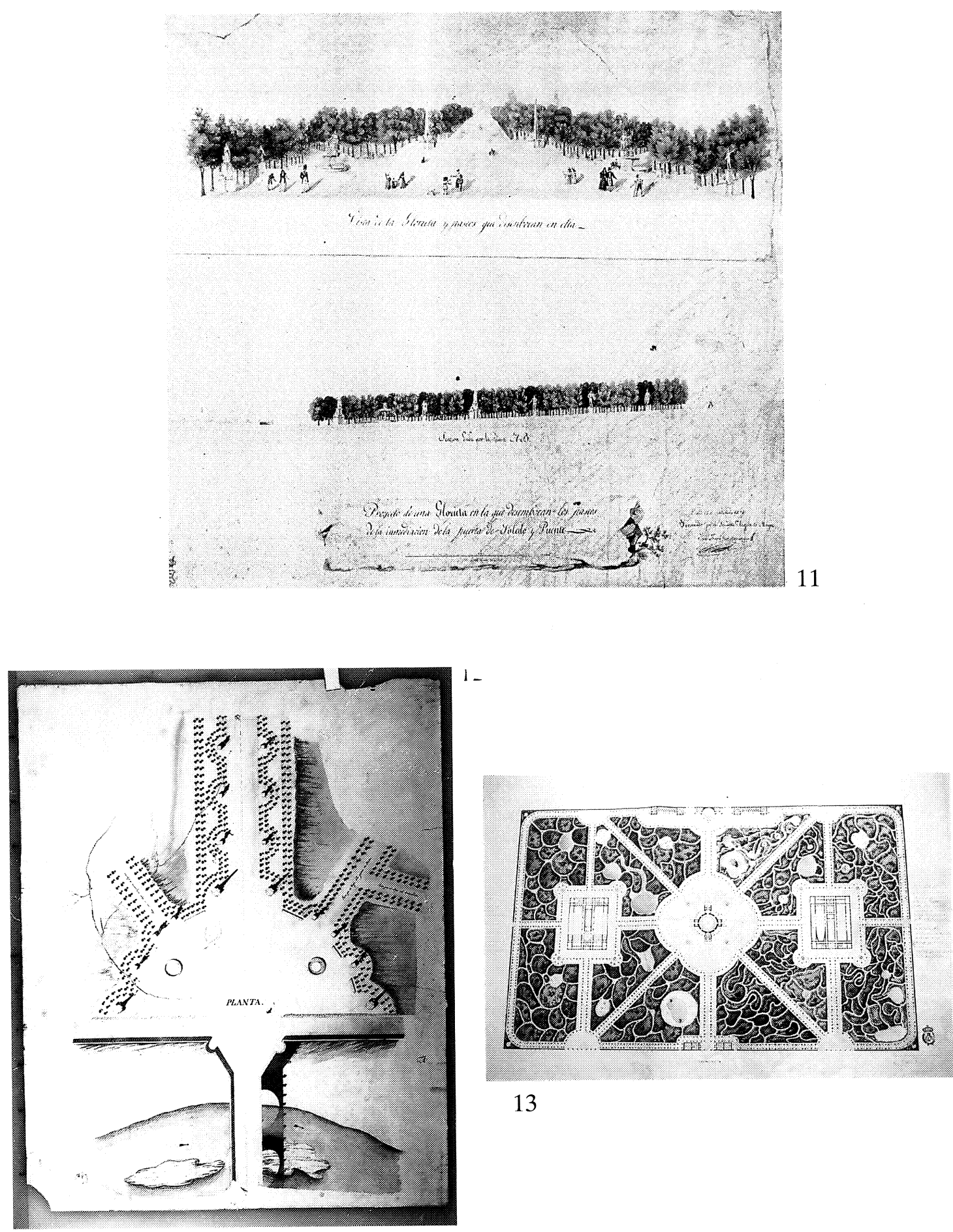

13

Figuras 11-13. Francisco Javier Mariátegui, Glorieta de las Pirámides. Alzado y sección. 1831. Francisco Javier Mariátegui, Glorieta de las Pirámides. Planta. 1831. Vicente Miranda, Jardín de recreo público, 1853. 
Moro, para el cual realiza diversos proyectos entre 1844 y $1847^{35}$, de trazado geométrico clásico por imperativo del decoro y la necesidad de adecuarse al edificio. Diseña también unos jardines para el cementerio de la Sacramental de San Luis, a la vez que prosiguen sus intervenciones en la Real Florida, el Casino de la Reina, la Casa de Campo y Vista Alegre. Aunque a veces recurra al trazado regular, su actitud es inequívocamente romántica y también en sus jardines demuestra la libertad en el diseño propia de la época en la triunfaban las fórmulas escénicas y pintorescas de jardín, si bien comenzaban también las primeras revalorizaciones historicistas que hacen volver al diseño geométrico en elgunas partes del jardín, combinándolo con el diseño paisajista. En esta línea realiza un sugerente proyecto de parque inglés para el Buen Retiro ${ }^{36}$ en la zona de los Jerónimos, iglesia que él mismo estaba restaurando. Su proyecto de un Castillo que se ha de construir en el jardín reservado de S.M. en el Real Sitio del Buen Retiro ${ }^{37}$, de 1846, aunque no presenta ninguna novedad temática es un precioso ejemplo de «capricho arquitectónico», típico de los jardines paisajistas.

Nos detendremos algo en las obras de la Plaza de Oriente, plaza que trataba de poner en contacto el Palacio Real con la ciudad en una política urbana y arquitectónica de timbre monumental y que terminará siendo un espacio público especialmente dedicado al esparcimiento y el paseo. A la vuelta de Fernando VII se pensó de nuevo en realizar una plaza a oriente de Palacio con un nuevo teatro de Corte. El proyecto fue encargado en 1815 a Isidro González Velázquez, que por los mismos años concibió otro para la terminación de la Plaza de Armas. La plaza sería de trazado ultrasemicircular, semejante en forma y función a la Galería que vimos de Ventura Rodríguez para el Prado. Estaría ajardinada y en su centro se situaría un templete monóptero. El arquitecto consideraba este proyecto su obra maestra $\mathrm{y}$, en efecto, de haberse realizado habría significado su consagración como uno de los arquitectos neoclásicos mejores de Europa ${ }^{38}$, pero una vez realizadas una parte importante de las obras, en 1833 éstas fueron derribadas. En 1844 Narciso Pascual y Colomer revisa el proyecto realizado para esta plaza en 1842 por los ingenieros Merlo, Gutiérrez y Ribera. La zona central tenía forma de elipse y estaría flanqueada por dos espacios rectangulares ajardinados - en lugar de manzanas de casas como en el proyecto de los ingenieros- que se plantarían con setos de gleditzias y aligustre, pinos, cedros, diversos arbustos y flores, fundamentalmente rosas ${ }^{39}$. Ya a finales de 1843 se realizó el nuevo monumento en el centro de la plaza, donde se colocaría la estatua ecuestre de Felipe IV. Alrededor se trazaron parterres geométricos de boj con flores y árboles frutales, adornados con fuentes y bancos de piedra. Esta zona central se rodeó de una verja de hierro sobre basamento de caliza circundada por un paseo elevado con dos filas de acacias ${ }^{40}$, entre las cuales se dispusieron cuarenta estatuas de las que habían sido realizadas como remate del Palacio Real y que nunca llegaron a ocupar su posición. En 1861, Francisco Viet reforma los cuadros laterales, cambiando el trazado regular por un diseño paisajista con praderas y variadas especies de árboles.

\footnotetext{
35 Cfr. Sancho, José Luis: Jardines de Palacio, Avapiés, Madrid, 1994, p. 95.

${ }^{36}$ A.G.P., planos 1403 y 5272, fechados en 1847.

37 A.G.P., plano 3939.

38 Navascués Palacio, Pedro: «Isidro González Velázquez» en VV.AA.: Madrid no construido: imágenes arquitectónicas de la ciudad prometida, pp. 82-85.

39 Los planos 7 y 1982 a 1985 del A.G.P. pertenecen a las reformas que realizó Pascual y Colomer en la Plaza de Oriente.

${ }_{40}$ Ariza, Carmen: «En época de Isabel II, creación y mejoras de los jardines madrileños pertenecientes a la corona», Reales Sitios, n. ${ }^{\circ} 88,1986$, pp. 31-34.
} 
En las mismas fechas que se proyecta la forma definitiva de la Plaza de Oriente, durante la regencia de Espartero, se están realizando mejoras y nuevos proyectos en el Retiro ${ }^{41}$, en aquellas zonas a las que el público podía acceder. Se trata del Paseo de las Estatuas, que parte desde el Estanque Grande hacia occidente y que también se adornará con las estatuas de la cornisa de Palacio, y de la restauración del Parterre en cuya cabecera se colocorá una bella fuente clasicista y la estatua de Daoiz y Velarde. También se realizó un sencillo proyecto de calles diagonales en el Campo Grande. Es curioso que en pleno apogeo del jardín paisajista en las casas de recreo de la aristocracia, y en plena expansión del romanticismo madrileño, para los proyectos de jardinería pública se siga prefiriendo el trazado geométrico y regular propio de épocas anteriores.

Hemos dejado para el final el tema de los jardines de recreo públicos, por ser el que expresa de una manera más inequívoca la vocación de la jardinería urbana decimonónica. Los llamados Jardines de Recreo, fueron una de las grandes novedades de la jardinería urbana de este siglo, junto con la creación de los grandes parques públicos, para el esparcimiento de la población durante el verano. Larra, ya había propuesto en 1834 la creación de parques y atracciones estivales bajo la influencia del XIX francés ${ }^{42}$.

Éstos eran zonas arboladas donde previo pago de una entrada, se podía disfrutar de diversos espectáculos (obras de teatros, conciertos, fuegos artificiales...) y diversiones (patinaje, etc...). Además había cafés, restaurantes... En Madrid se crearon varios jardines de este tipo, teniendo una gran acogida por parte del público: Jardines de las Delicias, Apolo, Tívoli, Portici, del Paraíso, del Sr. Price, el Elíseo madrileño, el de la Alhambra, los Jardines Orientales, Parque Rusia o Madrid Moderno, etc... el gran parque llamado Campos Elíseos, los jardines del Buen retiro, etc... llegarán a tener un carácter popular ${ }^{43}$.

Como ya hemos comentado, el proyecto de Vicente Miranda para su Jardín de Recreo Público, presenta, por primera vez en estos ejercicios académicos, una temática totalmente puesta al día. No tenía referencias inmediatas en España, pues aún no existía ningún ejemplo verdaderamente representativo en esas fechas, por lo que para el programa recurriría a referencias extranjeras y lo materializaría en una serie de edificios e instalaciones razonablemente clasicistas. Para la formalización del trazado del jardín siguió un esquema típico de la época, combinanado ejes rectilíneos y disposiciones simétricas con diseños irregulares y sinuosos en el interior de las zonas que limitaban los ejes regulares. Hay que puntualizar, sin embargo, que esta disposición mixta, es más propia de los primeros trazados de transición, cuando estaba surgiendo el estilo paisajista, que ya en el XIX, cuando se incluían zonas de trazado geométrico yuxtapuestas a las zonas irregulares en un intento de recuperación historicista de anteriores estilos jardineros. En España es muy difícil discernir entre los trazados que siguen esta fórmula historicista y aquellos que son aún representaciones tímidas del nuevo estilo y por ello conservan elementos rectilíneos. De todas maneras, el empleo de ejes regulares era frecuente, como hemos podido comprobar, en el diseño general o de «contorno» de los parques públicos, que luego desarrollaban en su interior toda la profusión de formas y vegetación del estilo isabelino.

${ }^{41}$ Guerra de la Vega, Ramón: Jardines de Madrid: el Retiro, ed. del autor, Madrid, 1983, pp. 47-48.

42 Larra, Mariano José de: «Costumbres. Jardines Públicos» en La Revista Española, 20-VI-1834. Publicado de nuevo en Arquitectura, n.. 39, 1922, pp. 309-311.

43 En Carmen Ariza: Jardines de Madrid en el siglo XIX, El Avapiés, Madrid, 1988, pp. 228-255 hay todo un capítulo dedicado a este tipo de establecimientos. Ver también, de la misma autora: «Los Jardines de Recreo del Buen Retiro», Koiné, n.․ 3, 1986, pp. 17-28 y «Jardines de recreo en Madrid: los llamados Campos Elíseos», Goya, n. 204, 1988, pp. 343-351. 